\title{
CDS RISK PRIMLERI iLE DIŞ BORÇLANMA iLIŞKISi: SIMETRIK VE ASIMETRIK NEDENSELLIK ANALIZi
}

\author{
Ömer AKKUŞ
}

\begin{abstract}
Öz
Bu çalışma Türkiye'nin kamu ve özel sektör dış borcu ile kredi temerrüt swapları (CDS) arasındaki ilişkiyi 2000Q4-2019Q1 dönemi verilerinden yaralanarak incelemektedir. Kamu ve özel sektör dış borcu ile CDS arasındaki simetrik nedensellik ilişkisi Hacker ve Hatemi-J (2006) nedensellik testi aracılı̆̆ıla incelenirken değişkenlerin pozitif ve negatif bileşenleri arasındaki ilişki Hatemi-J (2012) asimetrik nedensellik testi aracılığıyla incelenmektedir. Çalışmanın ampirik bulguları kamu dış borçlanması ile CDS primleri arasında çift yönlü bir nedensellik ilişkisinin varlığını ortaya koyarken özel sektör dış borcu ile CDS primleri arasında herhangi bir nedensellik ilişkinin bulunmadığı tespit edilmiştir. Kamu dış borcundaki pozitif bir şokun CDS primlerindeki pozitif ve negatif şokların bir nedeni olduğu ancak kamu dış borcundaki negatif bir şokun CDS primi bileşenlerinin bir nedeni olmadığı belirlenmiştir. Özel sektör dış borcundaki pozitif ve negatif şokların CDS risk primindeki pozitif şokların bir nedeni olduğu belirlenirken CDS risk primlerindeki pozitif şokun da özel sektör dış borcundaki negatif şokun bir nedeni olduğu sonucuna ulaşılmaktadır.
\end{abstract}

Anahtar Kelimeler: CDS, Dış Borç, Asimetrik Nedensellik

JEL SInıflandırması: H63, F34

\section{THE RELATIONSHIP BETWEEN CDS RISK PREMIUM AND EXTERNAL DEBT: SYMMETRIC AND ASYMMETRIC CAUSALITY ANALYSIS}

\begin{abstract}
This study examines relationship between Turkey's public and private sector external debt and credit default swaps (CDS) for the period 2000Q4-2019Q1. The symmetric causality relationship between public and private sector external debt and CDS is analyzed by the Hacker and Hatemi-J (2006) causality test. The relationship between the positive and negative components of the variables is examined through the Hatemi-J (2012) asymmetric causality test. While the empirical findings of the study reveal the existence of a bidirectional causality relationship between public external debt and CDS risk premium, there was no causal relationship between private sector external debt and CDS risk premium. It has been determined that a positive shock in public external debt is a cause of positive and negative shocks in CDS premiums, but a negative shock in public external debt is not a cause of CDS premium components. While it is determined that positive and negative shocks in private sector external debt are a cause of positive shocks in CDS risk premium, it is concluded that positive shock in CDS risk premiums is a cause of negative shock in private sector external debt.
\end{abstract}

Keywords: CDS, External Debt, Asymmetric Causality

JEL Classification: H63, F34

1 Dr. Öğr. Üyesi, Samsun Üniversitesi, iktisadi Idari ve Sosyal Bilimler Fakültesi, Ekonomi ve Finans Bölümü, omer.akkus@samsun.edu.tr, ORCID:0000-0003-4738-2694 


\section{Giriş}

Son dönemin en önemli finansal yeniliklerinden biri olarak değerlendirilen, kredi temerrüt swapları (CDS) son zamanlarda giderek artan eleştirilere maruz kalmaktadır. 2007' de patlak veren Subprime mortgage krizi küresel ekonomi için ciddi sonuçlar doğurmuştur. Çok sayıda çalışmada bu krizin nedenleri değerlendirirken önemli ölçüde tercih edilen bir türev olan kredi temerrüt swaplarına vurgu yapılmaktadır. Kredi temerrüt swapları ülke riskleri için vekil değişken olarak değerlendirilmektedir (Ho, 2016; Ismailescu ve Phillips, 2015). Bir CDS sözleşmesi en iyi şekilde, belirli bir firmanın veya işletmenin borcunu temerrüde düşürmesi durumunda basit bir sigorta sözleşmesi olarak düşünülmektedir. Kredi temerrüt swap sözleşmesinin ilk tarafı olarak koruma satın alan alıcı, herhangi bir şirket tarafından ihraç edilen bir tahvilin temerrüte düşme olasılığına karşı sigortalamak istemektedir. Tahvil ihraç eden şirket referans tüzel varlık olarak adlandırılırken tahvilin kendisi referans yükümlülüğü olarak belirlenmiştir. Sözleşmenin ikinci tarafı olan koruma satıcısı, referans varlık tarafından temerrütle ilişkili riski üstlenmeye isteklidir. Bir temerrüt durumunda referans tüzel kişi tarafından, koruma satıcısı referans yükümlülüğü koruma alıcısından nominal değerinde almayı kabul etmektedir. Buna karşılık, koruma satıcısı koruma alıcısından periyodik bir ücret almaktadır. Eğer sözleşmenin ömrü boyunca temerrüt durumu ortaya çıkmaz ise sözleşme vade tarihinde sona ermektedir (Longstaff vd., 2005).

CDS, belirli bir firma veya ülkedeki iki taraf arasında kredi riskinin aktarılmasına izin veren bir sözleşmedir. Bir CDS alıcısı, sözleşmenin vadesi veya kredi durumu meydana gelinceye kadar CDS satıcısına düzenli olarak prim ödemeyi kabul etmektedir. Kredi olayı durumunda CDS alıcısına, tahvilin nominal değeri ile kredi olayının gerçekleşmesinden sonraki piyasa değeri arasındaki farka eşit olarak oluşan zarar tazmin edilerek ödenmektedir. CDS marjları yalnızca temerrüt riski tarafından belirlenmektedir. Ayrıca CDS piyasası önemli bilgi birikimine sahip yatırımcıların yaptıkları işlemler sayesinde oldukça likit bir piyasa haline gelmiştir (Tolikas ve Topaloglou, 2017; Kapadia ve Pu, 2012). CDS marjlarının temerrüt olasılığını tam olarak temsil edip etmediği sorusu belirsiz kalmaktadır. Piyasa likiditesinin manipülasyonu genellikle spekülatif saldırıların yönlendirildiği birincil mekanizma olduğu vurgulanmaktadır. Bu yüzden, kredi piyasaları spekülasyona maruz kalıyorsa, CDS spreadlerinin bileşenlerini ayrıntılı bir şekilde incelemek ve bunun temerrüt riski ve likiditesinin ne kadarını açıkladığını tam olarak belirlemek çok önemli bir hal almaktadır (Calice vd., 2013).

Piyasa katılımcıları, temerrüt olasılığının oldukça düşük olduğunu bilirler ve bu durum herhangi bir temerrüt korkusu olmadan prim almak için CDS sözleşmelerinin satışı ve spekülasyonu için onları teşvik edebilmektedir. Satış tarafı satın alma tarafından daha güçlü ise, o zaman temerrüt riski değişmemiş olsa bile CDS marjlarını etkileyebilecek bir ticaret dengesizliğine sahip olunmaktadır. Bu durum likiditenin CDS fiyatlandırması üzerinde güçlü bir etkiye sahip olduğunu kanıtlamaktadır (Badaoui vd., 2013). 2008 küresel krizinden önce kredi piyasalarında yapılan işlemler, kurumsal kredi riski veya menkul kıymetleştirme araçları gibi özel sektör araçlarına yoğunlaşmaktaydı.

Lehman Brothers'ın 2008 sonbaharında çöküşü, gelişmiş ülke borçlarının temerrüt riskinin temelde yeniden değerlendirilmesine yol açmıştır. Bankalar için yaygın ve büyük ölçekli devlet desteği ve ekonomik aktivitenin daha fazla hareketlemesine yönelik diğer teşvik önlemleri, kamu kesimi açıklarını en son II. Dünya Savaşı'ndan sonra görülen seviyelere hızlı bir şekilde yükselmesine neden olmuştur (Panetta vd., 2009). 2010'un ilk yarısında pek çok ülkedeki kamu borç piyasaları benzeri görülmemiş bir stres altında kaldı. Örneğin Yunanistan devlet tahvillerinde büyük satışlar gözlendi ve Yunan tahvillerinde CDS spreadleri 1000 baz puanın üzerine çıktı. Yunanistan kamu kesimi açığı GSYIH'nın\%6'sından \%12,7 seviyesine çıktığı gözlemlendi. Bu olay kamu kesimi borç krizini başlatmış ve Yunanistan, İrlanda ve Portekiz'de büyük finansal müdahalelerde bulunulması zorunlu hale gelmiştir (Calice vd., 2013). Geleneksel olarak, gelişmiş ülkeler tarafından ihraç edilen menkul kıymetlere ilişkin devlet borcunun değerlemesinin, temerrüde düşme olasılığı çok düşük bir ihtimal olarak değerlendirilmektedir. Bu nedenle, borçlanma yapısı tipik olarak temerrüt 
riskinden ziyade faiz oranı veya likidite riskine yönelik yapılmaktadır. Gelişmiş ülkelerde temerrüte düşmenin olmayışı, devlet tahvillerinin uzun dönemli risksiz faiz oranı için yaygın olarak kullanılan iyi bir vekil olduğuna dair varsayımı desteklemektedir (Fontana ve Scheicher, 2010).

Diğer taraftan özel sektörün borç alma yapısında önem yeri olan firmalar dış finansman ihtiyaçlarını karşılamak için birden fazla borç türü kullanmakta ve toplam kaldıraçlarında önemli bir değişiklik göstermese bile borç kompozisyonlarında yıldan yıla önemli değişiklikler yaşamaktadırlar. Firmalar yatırımcılarına borç senetleri ihraç edebilir veya doğrudan ticari bankalar gibi finansal aracılardan borç alarak finansman ihtiyaçlarını karşılayabilmektedir. Bir CDS piyasasının olması sadece alternatif korunma ve spekülasyon fırsatları sağlamakla kalmaz, aynı zamanda referans firmaların ve alacaklılarının teşviklerini de değiştirir. Bu nedenle, CDS'lerin hem kamu borçlanması hem de özel sektör borçlanmasının gerçekleştiği kredi piyasası üzerinde önemli bir etkisinin olabileceği düşünülmektedir (Chen vd., 2018).

Bu çalışmanın amacı dış borçlanma ile CDS risk primleri arasındaki ilişkinin ortaya çıkarılmasıdır. Çalışmayı literatürdeki diğer çalışmalardan ayıran iki önemli husus bulunmaktadır. İlk olarak dış borcun özel sektör borcu mu yoksa kamu kesimi borcu mu olduğu ayrımına gidilmektedir. Böylece CDS primlerindeki yükseliş veya düşüşlerin borçlanmayı gerçekleştiren kesimlerin borçlanma yapısında önemli ölçüde bir değişiklik gösterip göstermediğinin belirlenmesi amaçlanmaktadır. Diğer bir husus ise şokların yapısı ile alakalı olarak özel sektör dış borcu, kamu kesimi dış borcu ve CDS primlerindeki pozitif veya negatif şokun etkilerinin ayrı ayrı analiz edilerek ortaya çıkarılması amaçlanmaktadır.

\section{Literatür}

Literatürde kredi risk primleri ve dış borç arasındaki ilişki incelenirken öncelikle CDS risk primini nelerin etkilediği konusuna odaklanılmakta sonrasında ise CDS priminin belirleyicilerinden birisi olarak değerlendirilen dış borç konusu irdelenmektedir. Pek çok çalışma, devlet tahvillerine ilişkin kredi temerrüt swap spreadleri ile çeşitli makroekonomik değişkenler arasındaki ilişkiyi incelemiştir. Bu çalışmalar, borç ve mali değişkenlerin, rezervlerin, GSYiH büyümesinin ve çeşitli vadelerdeki faiz oranlarının kredi temerrüt swap spreadlerini açıklamada önemli bir rol oynayıp oynamadığını incelemektedirler. Bu ilişkiler Eichengreen ve Mody (1998); Kamin ve Kleist (1999); Min (1998) çalışmalarında ayrıntılı olarak ele alınmaktadır. Bu çalışmalarda çeşitli ampirik kanıtlar bulunsa da özellikle belirli ülkeler veya bölgeler söz konusu olduğunda ve belirli zaman aralıkları için, kredi temerrüt swap spreadlerinin istikrarlı ve önemli belirleyicileri üzerindeki tartışma hiçbir şekilde tam olarak çözülememiştir (Bellas vd., 2010).

Bulow ve Rogoff (1989) döviz kuru değişimlerinin ülkenin ticaret koşulları üzerinde doğrudan bir etkiye sahip olduğunu, bunun da ülkenin dolar geliri üretme kabiliyetini etkilediğini ve ülkelerin böylece dış borç ödemelerini gerçekleştirebildiği vurgulamaktadır. Hernandez-Trillo (1995), temerrüt olasılığını tahmin etmek için bir ülke kredi piyasası modeli oluşturulmuştur. Model, dengenin kredi tayınlaması gerektirdiğini ve temerrüt olasılığının belirleyicileri olarak borç seviyesini ve LIBOR spreadleri içermesinin yetersiz olduğunu vurgulamaktadır. Temerrüt olasılığını açıklamada açıklık derecesi, uluslararası rezervler ve risksiz faiz oranının önemli belirleyiciler olduğu belirtilmektedir. Ampirik sonuçlar, modelin 33 borçlu ülke için geçerli olduğunu ortaya koyarken ekonomik serbestleşmenin temerrüt olasılığını azalttığını ve böyle bir politikanın kredibiliteyi arttırdı̆̆ını göstermektedir.

Blanco vd. (2005) denge koşulu olarak parite ilişkisi ile CDS fiyatlarının ve kredi spreadlerinin teorik denkliğini test etmektedir. Pariteden iki tür sapma tespit edilmektedir. Illk olarak, üç firma için CDS fiyatlarının, CDS'lerin sözleşme şartnamesindeki kusurlardan ve kredi spreadlerinin hesaplanmasındaki ölçüm hatalarından kaynaklanan uzun vadeli kredi spreadlerinden önemli ölçüde yüksek olduğu belirlenmiştir. İkinci olarak ise CDS fiyatlarının fiyat belirleme sürecinde kredi spreadleri üzerindeki artışa bağlı olarak diğer tüm şirketler için pariteden kısa süreli sapmalara sahip olduğu belirlenmiştir. 
Longstaff vd. (2005) Kurumsal spreadlerin temerrütte olan ve temürrütte olmayan bileşenlerin boyutuyla ilgili doğrudan ölçümler elde etmek için kredi temerrüt swaplarındaki bilgileri kullanmaktadır. Çalışmada kurumsal spreadlerin çoğunun temerrüt riskinden kaynaklandığı tespit edilmiştir. Ayrıca, temerrütte olmayan bileşenin zamanla değiştiği ve tahvile özgü likitsizlik ölçülerinin yanı sıra tahvil piyasasının likiditesinin makroekonomik ölçümleriyle de ilişkili olduğu sonucuna ulaşmışlardır.

Mellios ve Paget-Blanc (2006) Hem ekonomik hem de politik faktörlerin ülke kredi notları üzerinde önemli bir etkisinin olduğunu dokuz değişkenden oluşan sıralı lojistik modeli kullanarak incelemektedir. Teorik temelden hareketle, kişi başına gelir, kamu harcamaları ve reel döviz kurundaki değişimlerin derecelendirme üzerinde olumlu bir etki yaratırken, enflasyon oranının negatif etki yarattığı sonucuna ulaşılmaktadır.

Hassan (2013) Amerika Birleşik Devletleri, Avrupa ve Asya-Pasifik piyasalarındaki kredi temerrüt swaplarının belirleyicilerini doğrusal regresyon aracılığıyla incelemektedir. Amerika Birleşik Devletleri ve yurtdışından elde edilen bulgular, temerrüt riskinin teorik belirleyicileri ile kredi temerrüt swaplarının gerçek piyasa fiyatlandırması arasındaki önemli ilişki olduğunu göstermektedir.

Wang vd. (2013) Latin Amerika devlet kredi temerrüt takas getirileri ile diğer finansal ülke borç belirleyicileri arasındaki zamanlararası nedensellik ilişkilerini araştırmaktadır. Ampirik sonuçlar, ülke CDS'lerindeki bilgilerin finansal belirleyicilere hem öncülük edebileceğini hem de geciktirebileceğini göstermektedir.

Eyssell vd. (2013) ülkeye özgü değişkenleri ve küresel değişkenleri kullanarak hem Çin'in CDS pazarının belirleyicilerini incelemekte hem de kredi temerrüt swap spread değişiklikleri ile hisse senedi getirileri arasındaki dinamik ilişkiyi ele almaktadır. Çin'in dış borçlarının GSYiH'ya oranını ülkenin dış borçlarını geri ödeyebilmesi için vekil değişken olarak kullanılmaktadır. Şanghay borsa endeksi getirilerinin oynaklığı ülkenin varlık değerinin oynaklığının bir ölçüsü olarak kullanılmaktadır. CDS ve hisse senedi getirileri arasındaki ilişkinin incelendiği çalışmada fiyat keşfinin dışsal faktörleri kontrol ettikten sonra öncelikle CDS pazarında gerçekleştiği belirlenmiştir.

Ismailescu ve Phillips (2015) tahvil piyasasında CDS alım satımının belirleyicilerini ve etkilerini analiz etmektedir. Illk olarak, CDS ticaretinin başlatılmasını takiben spread ayarlanma verimliliğinin belli bir teminatın üzerinde öncelik hakkı veren tahvil için iyileştiğini ve bu kazançların çoğunlukla yüksek temerrüt riski olan ülkeler tarafından sağlandığı belirlenmiştir. İkincisi, tüm ihraççıların borçlanma maliyetleri CDS ticaretinin başlatılmasının ardından düşmekte ve en büyük temerrüt riski en yüksek ülkeler tarafından elde edilmektedir. Çalışmadan elde edilen sonuçlar, CDS primlerine ilişkin piyasada alım satımların yapılması sonucunda artan bilgi verimliliğinin, bilgi asimetrisinin en belirgin olduğu ülkeler için borç maliyetinde bir azalma ile ilişkili olduğunu göstermektedir.

Aizenman vd. (2016) 2004-2012 döneminde gelişmekte olan piyasaların CDS spreadlerini çeşitli ekonomik temellerinin görece önemini ampirik olarak değerlendirmektedir. CDS spreadleri ile enflasyon, ülke kırılganlığı, dış borç ve emtia ticaret oynaklığı arasında olumlu bir ilişki gözlenirken, ticari açıklık ve mali denge / GSYiH oranı arasında negatif bir ilişkinin olduğu sonucuna ulaşılmıştır. Ancak, ülke riskinin fiyatlandırılmasında ekonomik temellerin göreceli önemi zaman içinde değişmektedir. 2008-2009 krizi öncesi dönemde ülke riskinin fiyatlandırılmasında temel faktörler ticari açıklık ve ülkenin kırılganlığı iken kriz döneminde bu faktörler dış borcunun GSYiH'ya oranı ve enflasyon, kriz sonrası dönemde ise enflasyon ve kamu borcunun GSYiH'ya oranı olduğu tespit edilmiştir.

Kocsis ve Monostori (2016) CDS belirleyicilerini Doğu Avrupa verileri özelinde incelemektedir. Yurtiçi faktörlerin büyük ölçüde ülkeler arasındaki risk farklılıklarını açıklama gücünden dolayı CDS spread varyansını küresel faktörlerden daha fazla açıkladığı sonucuna ulaşılmaktadır. Ekonomik 
önemi açısından, kurumsal politik güç faktörünün öne çıktığı ve CDS spreadleri üzerindeki etkilerin zamanla değişen olduğu belirlenmiştir.

Qian vd. (2017) Japonya'nın kredi temerrüt swapları ve makroekonomik temelli finansal göstergeleri arasındaki etkileşimi inceleyerek, Japonya'nın kredi riskinin doğasını anlamaya çalışmaktadırlar. Küresel finans piyasasından potansiyel bulaşma göz önünde bulundurulmakta ve CDS spreadleri ile makroekonomik temeller arasında ters nedensellik ilişkisi de belirlenmeye çalışılmaktadır. Lehman Brothers'ın iflası ile küresel borsalardan Japonya'nın kredi piyasasına bulaşmanın gerçekleştiğine ilişkin güçlü kanıtlar bulunurken Avrupa'daki borç krizinin yalnızca geçici etkilerinin olduğu belirlenmiştir.

Akkaya (2017) 2008 küresel kriz döneminde 2016 yılına kadar Türkiye'nin CDS risk primlerini etkileyen içsel değişkenleri belirlemeye çalışmaktadır. Çalışmada altın fiyatları ve BisT getiri endeksi dışsal değişkenler olarak modele dahil edilmektedir. İçsel değişken olarak belirlenen iç borç stoku ve kısa vadeli dış borç stokunun istatistiki olarak modelde anlamlı olmadığı belirlenmiştir.

Yılmaz ve Ünlü (2018) Türkiye'nin ekonomik kırılganlığının gözlemlenebilir ve ölçülebilir göstergelerinden birinin kredi temerrüt swapları olduğunu belirtmektedir. Bu göstergenin Türkiye ekonomisinin temerrüt olasılı̆̆ını temsil ettiği ve birçok makroekonomik göstergeden etkilendiği vurgulanmaktadır. Elde edilen bulgular, cari işlemler hesabından döviz kuruna ve döviz kurundan CDS'ye bir zincirleme etkinin olduğuna dair nedenselliğin varlığını kanıtlamaktadır. Ayrıca elde edilen eşbütünleşme katsayıları döviz kuru ve CDS arasında pozitif bir ilişki olduğunu cari işlemler hesabı ile CDS arasında ise istatistiki olarak anlamlı bir ilişki bulunamadığını göstermektedir. Kılcı (2019) CDS ile dış borç arasındaki ilişkiyi nedensellik ve eşbütünleşme testleri aracılı̆̆ıyla ortaya çıkarılmaya çalışmaktadır. Elde edilen bulgular dış borcun CDS risk primleri üzerinden kısa dönemde bir etkiye sahip olmadığını ancak bu etkinin uzun dönemde var olduğunu göstermektedir.

Akçelik ve Fendoğlu (2019) Gelişmekte olan yedi piyasa ekonomisi için dinamik panel eşik sabit etkiler modeli kullanılmışlardır. Analiz sonuçları küresel risk iştahı düştüğünde cari işlemler dengesi, uluslararası rezervler veya mali bütçe dengesinde bir bozulma ve finansal olmayan şirketlerin döviz borçlarındaki artışın ülke risk primini daha güçlü bir şekilde artıracağını göstermektedir. Ancak küresel risk iştahı ile uyumlu olduğu durumlarda gelişmekte olan piyasa ekonomileri için ülke risk primi dinamikleri için yurtiçi makroekonomik temellerin daha az önemli olduğuna dair kanıtlar sunulmaktadır.

\section{Veri Seti ve Yöntem}

Değişkenler arasındaki nedensellik ilişkisi ekonomi biliminin en temel ve en önemli konuları arasında yer almaktadır. Granger (1969) tarafından uygulamalı yöntem olarak literatüre kazandırılan Granger nedensellik yöntemi geçmişteki bir olayın, şimdiki zamandan veya gelecekten kaynaklanamayacağı fikrine dayanmaktadır. Dolayısıyla, bir olay başka bir olaydan önce gerçekleşirse, nedensellik yalnızca ilk olaydan ikincisine doğru gerçekleşebilir. Granger, bir değişkendeki hareketlerin sistematik olarak başka bir değişkendeki hareketlerden önce olup olmadığını test etmek için bir test istatistiği formüle etmiştir. Granger nedensellik, bir değişkenin geçmiş değerlerinin bilgi kümesine dahil edilmesinin başka bir değişkenin tahminini iyileştirip iyileştiremeyeceğini ortaya koyabilme amacıyla belirlenmektedir (Hacker ve Hatemi-J, 2006: 1489). Değişkenlerin eşbütünleşme olmadan birinci dereceden bütünleşik $I(1)$ olduğu biliniyorsa değişkenlerin birinci dereceden farkında bir VAR tahmini yapılabilir ve böylece geleneksel asimptotik teori VAR modelindeki hipotez testi için geçerli olmaktadır. Sonuç olarak bir VAR modeli tahmini için değişkenlerin bütünleşme ve eşbütünleşme derecelerinin belirlenmesi gerekmektedir (Toda ve Yamamoto, 1995: 226).

Toda ve Yamamoto (1995) VAR süreçlerinde birim kökler olabileceği zaman karşılaşılan hipotez testindeki sorunların üstesinden gelmek için basit bir yol önermektedir. Zaman serisi verilerinin entegrasyon ve eşbütünleşme özelliklerini çok az dikkate alarak, serilerin düzey seviyeleri ile VAR tahmin edip Wald kriterini uygulayarak katsayılar üzerindeki doğrusal veya doğrusal olmayan 
kısıtlamalar test edilebilmektedir. Hacker ve Hatemi-J (2006) Wald kriterinine ilişkin test istatistiğinin örneklem sayısının az olduğu durumlarda zayıf olabileceğini ve bu yüzden geleneksel asimptotik dağılım kullanmak yerine bootstrap simülasyonuna dayalı dağılımın daha güçlü olduğunu vurgulamaktadır. Hatemi-J (2012) VAR modelinde seçilen gecikme uzunluğunun önsel bilgi ile seçilmesinin test istatistiğinin dağılımını etkileyeceğini bu yüzden Hacker ve Hatemi-J (2006) çalışması geliştirilerek optimal gecikme uzunluğu bootstrap simülasyonuyla belirlenmektedir. Verileri kümülatif pozitif ve negatif bileşenlere ayırma fikri Granger ve Yoon (2002) çalışmasına dayanmaktadır. Değişkenler arasında belirlenen ilişkilerin farklı, pozitif ve negatif şoklar arasındaki ilişkilerin ise farklı olabileceği vurgulanmaktadır. Ancak yazarlar bu yaklaşımı saklı eşbütünleşme olarak adlandırdıkları eşbütünleşmeyi test etmek için kullanmaktadırlar. Hatemi-J (2012) ise bu çalışmayı nedensellik analizine genişletmekte ve pozitif ve negatif şokların farklı nedensel etkileri olabileceği için asimetrik nedensellik testi olarak adlandırmaktadır (Hatemi-J, 2012). Aşağıdaki rassal yürüyüş süreçleri olarak tanımlanan $y_{1 t}$ ve $y_{2 t}$ değişkenleri arasındaki nedensel ilişkiyi araştırmakla ilgilenildiği varsayılarak;

$$
y_{1 t}=y_{1 t-1}+\varepsilon_{1 t}=y_{10}+\sum_{i=1}^{t} \varepsilon_{1 i}
$$

ve

$y_{2 t}=y_{2 t-1}+\varepsilon_{2 t}=y_{20}+\sum_{i=1}^{t} \varepsilon_{2 i}$

$t=1,2, \ldots T$ iken $y_{10}$ ve $y_{20}$ başlangıç değerleri, $\varepsilon_{1 i}$ ve $\varepsilon_{2 i}$ değişkenleri beyaz gürültü hata terimlerini göstermektedir. Pozitif ve negatif şoklar sırasıyla $\varepsilon_{1 i}^{+}=\max \left(\varepsilon_{1 i}, 0\right), \varepsilon_{2 i}^{+}=\max \left(\varepsilon_{2 i}, 0\right)$, $\varepsilon_{1 i}^{-}=\min \left(\varepsilon_{1 i}, 0\right)$ ve $\varepsilon_{2 i}^{-}=\min \left(\varepsilon_{2 i}, 0\right)$ şeklinde tanımlanmaktadır. Bu nedenle $\varepsilon_{1 t}=\varepsilon_{1 i}^{+}+\varepsilon_{1 i}^{-}$ve $\varepsilon_{2 t}=\varepsilon_{2 i}^{+}+\varepsilon_{2 i}^{-}$biçiminde ifade edilebilmektedir. Buradan hareketle

$$
y_{1 t}=y_{1 t-1}+\varepsilon_{1 t}=y_{1,0}+\sum_{i=1}^{t} \varepsilon_{1 i}^{+}+\sum_{i=1}^{t} \varepsilon_{1 i}^{-}
$$

ve benzer şekilde

$$
y_{2 t}=y_{2 t-1}+\varepsilon_{2 t}=y_{2,0}+\sum_{i=1}^{t} \varepsilon_{2 i}^{+}+\sum_{i=1}^{t} \varepsilon_{2 i}^{-}
$$

olarak gösterilmektedir. Son olarak her değişkenin pozitif ve negatif şokları kümülatif bir biçimde $y_{1 i}^{+}=\sum_{i=1}^{t} \varepsilon_{1 i}^{+}, y_{1 i}^{-}=\sum_{i=1}^{t} \varepsilon_{1 i}^{-}, y_{2 i}^{+}=\sum_{i=1}^{t} \varepsilon_{2 i}^{+}$ve $y_{2 i}^{-}=\sum_{i=1}^{t} \varepsilon_{2 i}^{-}$

şeklinde tanımlanabilir. Kurulan model ile her bir pozitif ve negatif şokun temel değişken üzerinde kalıc bir etkisinin olduğu belirtilmektedir. Asimetrik nedensellik testinde pozitif ve negatif şoklar arasındaki nedensellik ilişkisi VAR modelinin tahminine dayalı olarak gerçekleştirilmektedir (Hatemi-J, 2012, 449).

Tablo 1: Tanımlayıcı İstatistikler

\begin{tabular}{cccc}
\hline Tanımlayıcı İstatistikler & CDS & Kamu Dış Borcu & Özel Sektör Dış Borcu \\
\hline Ortalama & 349.288 & 15.519 & 25.311 \\
Medyan & 243.796 & 13.319 & 24.668 \\
Maksimum & 1281.250 & 29.310 & 40.016 \\
Minimum & 127.026 & 9.844 & 15.105 \\
Standart Sapma & 273.541 & 4.906 & 6.611 \\
Çarpıklık & 2.005 & 1.375 & 0.355 \\
Basıklık & 6.198 & 4.080 & 2.242 \\
Jarque-Bera & 81.128 & 26.919 & 3.326 \\
Gözlem Sayısı & 74 & 74 & 74 \\
\hline
\end{tabular}


Çalışmada kullanılan değişkenlere ilişkin tanımlayıcı istatistikler Tablo 1'de sunumuştur. Veri setinin tanımlayıcı istatistikleri incelendiğinde 2000Q4-2019Q1 döneminde Türkiye'nin CDS risk primleri ortalamasının 349 olduğu bu dönemde ülke risk priminin en yüksek düzey olan 1281'e 2003Q1 döneminde ulaşıldığını ve 2012Q4 döneminde ise 127 puan ile ülke risk priminin en düşük olduğu dönem olarak göze çarpmaktadır. Kamu dış borcunun GSYIH'ya oranının \%29 ve en yüksek olduğu dönem 2002Q2 iken en düşük olduğu 2008Q3 döneminde bu oran \%9,8'dir. İncelenen dönemde özel sektör dış borcunun GSYiH'ya oranının ortalama \%25 olduğu Türkiye'de bu oranın en yüksek olduğu 2019Q1 döneminde \%40'ları görürken en düşük olduğu 2004Q1 döneminde ise bu oran \%15'tir.

Türkiye'nin dış borcunun bileşenlerinden kamu dış borcu ve özel sektör dış borcu ile CDS primleri arasındaki ilişki 2000-2019 dönemi çeyreklik verilerinden yararlanılarak araştırılmaktadır. Çalışmada kamu dış borcu ve özel sektör dış borcu ile CDS primleri arasındaki ilişkinin varlığı Hacker ve Hatemi-J (2006) nedensellik testi ve Hatemi-J (2012) asimetrik nedensellik testleri aracılığıyla ortaya çıkarılmaktadır. Hacker ve Hatemi-J (2006) nedensellik testi uygulanırken değişkenlerin bileşenleri dikkate alınmadan bir nedensellik ilişkisi ortaya çıkarılmaya çalışıırken Hatemi-J (2012) asimetrik nedensellik testinde ise değişkenler pozitif ve negatif bileşenlerine ayrılarak pozitif ve negatif bileşenler arasında nedensellik ilişkisi araştırılmaktadır.

\section{Ampirik Bulgular}

Çalışmanın bu bölümünde değişkenlere ADF ve Phillips-Perron birim kök testleri uygulanmış ve maksimum eşbütünleşme derecesi belirlenerek değişkenler arasındaki nedensellik ilişkisi Hacker Hatemi-J (2006) simetrik nedensellik testi ve Hatemi-J (2012) asimetrik nedensellik testleri aracılığıyla ortaya çıkarılmaktadır. CDS, kamu dış borcu ve özel sektör dış borcu değişkenlerine ait ADF ve Phillips-Perron birim kök sonuçları Tablo 2'de sunulmuştur.

Tablo 2: Birim Kök Sonuçları

\begin{tabular}{|c|c|c|c|c|}
\hline \multirow[b]{2}{*}{ Değişkenler } & \multicolumn{2}{|c|}{ ADF Birim Kök Testi } & \multicolumn{2}{|c|}{ Phillips-Perron Birim Kök Testi } \\
\hline & Sabit & Sabit ve Trend & Sabit & Sabit ve Trend \\
\hline Düzey & Test İstatistiği & Test İstatistiği & Test İstatistiği & Test İstatistiği \\
\hline CDS & -2.659 & -2.813 & -2.485 & -2.586 \\
\hline Kamu Dış Borcu & -1.467 & -0.814 & -1.362 & -1.010 \\
\hline Özel Sektör Dış Borcu & 1.446 & -1.891 & 1.204 & -1.857 \\
\hline \multicolumn{5}{|l|}{ Birinci Fark } \\
\hline CDS & -7.794 & -7.936 & -11.351 & $\underline{-11.925}$ \\
\hline Kamu Borcu & -4.691 & $\underline{-4.766}$ & $\underline{-4.557}$ & $\underline{-4.861}$ \\
\hline Özel Sektör Borcu & $\underline{-6.304}$ & $\underline{-6.616}$ & -6.257 & $\underline{-6.506}$ \\
\hline
\end{tabular}

_\%5 düzeyinde anlamlılıkları göstermektedir.

Çalışmada değişkenlere birim kök testi uygulanmış ve sonuçlar birbirini desteklediği için birim kök testlerinden ADF ve Phillips-Perron birim kök testleri raporlanmıştır. Birim kök testinden elde edilen sonuçlar her üç serinin birinci farkında durağan olduğunu göstermektedir. Değişkenler arasındaki nedensellik ilişkisinin belirlenmesinde kullanılan en yaygın yöntemlerden birisi Granger (1969) nedensellik testidir. Ancak Granger nedensellik testinde serilerin durağan hallerinin kullanılması gerekmektedir. Serilerin durağan hallerinin kullanılması zorunluluğu serilerde fark alma işleminin uygulanmasını gerektirebilmekte bu ise çoğu zaman kullanılan serilerde bilgi kayıplarına neden olmaktadır. Bu bilgi kayıplarının olmaması için Toda ve Yamamoto (1995) VAR modeline dayalı bir nedensellik yöntemi geliştirmiş ve bu yöntemle serilerin durağan halleri ile değil düzey halleri ile analize dahil edilmesine olanak sağlanmaktadır. Bu yöntemin uygulanması noktasında serilerin durağanlık dereceleri veya seriler arasında bir eşbütünleşmenin bulunup bulunmaması testin geçerliliğini etkilememektedir. Hacker ve Hatemi-J (2006) ARCH etkisinin olması ve hata terimi kalıntılarının normal dağılmaması durumunda Toda ve Yamamoto (1995) test istatistiklerinin hatalı sonuçlar ürettiğini bu yüzden de bootstrap simülasyonuna dayalı kritik 
değerler elde etmektedir. Tablo 3'te Hacker Hatemi-J testine nedensellik testi sonuçları sunulmuştur.

Tablo 3: Hacker ve Hatemi-J Nedensellik Test Sonuçları

\begin{tabular}{lccccc}
\hline Nedensellik & Test İstatistiği & \multicolumn{3}{c}{ Bootstrap Kritik Değerler } & Nedensellik \\
& & $\mathbf{1 \%}$ & $\mathbf{5 \%}$ & $\mathbf{1 0 \%}$ & ilişkisi \\
\hline CDS $\rightarrow$ Kamu Dış Borcu & 12.802 & 9.936 & 6.317 & 4.480 & Var \\
CDS $\rightarrow$ Özel Sektör Dış Borcu & 1.069 & 5.132 & 3.392 & 2.378 & Yok \\
Kamu Dış Borcu $\rightarrow$ CDS & 12.331 & 9.555 & 6.168 & 4.392 & Var \\
Özel Sektör Dış Borcu $\rightarrow$ CDS & 0.021 & 7.16 & 3.91 & 2.739 & Yok \\
\hline
\end{tabular}

Elde edilen bulgulara göre CDS primlerinden kamu dış borcuna doğru ve kamu dış borcundan CDS primlerine doğru çift yönlü bir nedenselliğin bulunduğu ancak CDS primleri ve özel sektör dış borcu arasında bir nedensellik ilişkisinin bulunmadığı belirlenmiştir. Bu durumda kamu dış borcundaki artışların ülke risk primini tetiklediği ya da tersine ülke risk primindeki artışların kamu dış borçlanmasının artmasının nedenleri arasında gösterilebilir.

Değişkenler pozitif ve negatif bileşenlerine ayrıldıktan sonrasında değişkenlere birim kök testleri uygulanmış elde edilen sonuçlar Tablo 4 ve Tablo 5'te sunulmuştur. Tablo 4'te pozitif bileşenlere ilişkin birim kök sonuçları sunulurken Tablo 5'te negatif bileşenlere ilişkin birim kök sonuçları sunulmuştur.

Tablo 4: Pozitif Bileşenler Birim Kök Sonuçları

\begin{tabular}{|c|c|c|c|c|}
\hline \multirow[b]{2}{*}{ Değişkenler } & \multicolumn{2}{|c|}{ ADF Birim Kök Testi } & \multicolumn{2}{|c|}{ Phillips-Perron Birim Kök Testi } \\
\hline & Sabit & Sabit ve Trend & Sabit & Sabit ve Trend \\
\hline Düzey & Test İstatistiği & Test İstatistiği & Test İstatistiği & Test İstatistiği \\
\hline $\mathrm{CDS}^{+}$ & -4.704 & $\underline{-4.496}$ & $\underline{-5.399}$ & -4.874 \\
\hline Kamu Dış Borcu ${ }^{+}$ & -1.865 & $\underline{-5.870}$ & -1.631 & -3.203 \\
\hline Özel Sektör Dış Borcu ${ }^{+}$ & 2.054 & -1.161 & 2.169 & -1.163 \\
\hline \multicolumn{5}{|l|}{ Birinci Fark } \\
\hline $\mathrm{CDS}^{+}$ & $\underline{-8.970}$ & -9.608 & $\underline{-8.945}$ & $\underline{-9.484}$ \\
\hline Kamu Dış Borcu ${ }^{+}$ & $\underline{-5.675}$ & $\underline{-3.559}$ & $\underline{-5.675}$ & $\underline{-5.646}$ \\
\hline Özel Sektör Dış Borcu ${ }^{+}$ & -7.295 & -7.693 & $\underline{-7.285}$ & $\underline{-7.639}$ \\
\hline
\end{tabular}

_\%5 düzeyinde anlamlııkları göstermektedir.

Tablo 5: Negatif Bileşenler Birim Kök Sonuçları

\begin{tabular}{lcccc}
\hline & \multicolumn{2}{c}{ ADF Birim Kök Testi } & \multicolumn{2}{c}{ Phillips-Perron Birim Kök Testi } \\
\hline Değişkenler & Sabit & Sabit ve Trend & Sabit & Sabit ve Trend \\
\hline Düzey & Test İstatistiği & Test İstatistiği & Test İstatistiği & Test İstatistiği \\
\hline CDS- $^{-}$ & $\underline{-4.991}$ & $\underline{-12.009}$ & $\underline{-5.807}$ & -3.175 \\
Kamu Dış Borcu- $^{-}$ & $\underline{-3.621}$ & -1.892 & $\underline{-2.914}$ & -0.707 \\
Özel Sektör Dış Borcu- & -1.943 & $\underline{-6.539}$ & -1.862 & -2.442 \\
\hline Birinci Fark & & & & \\
\hline CDS- $^{-}$ & -2.601 & -2.694 & $\underline{-7.530}$ & $\underline{-9.019}$ \\
Kamu Dış Borcu- & -2.073 & $\underline{-4.190}$ & $\underline{-4.281}$ & $\underline{-5.093}$ \\
Özel Sektör Dış Borcu- & $\underline{-4.867}$ & $\underline{-5.031}$ & $\underline{-5.720}$ & $\underline{-5.798}$ \\
\hline
\end{tabular}

_\%5 düzeyinde anlamlııkları göstermektedir.

Kamu dış borcu ve CDS primlerinin pozitif ve negatif bileşenlerine ilişkin Hatemi-J (2012) asimetrik nedensellik test sonuçları Tablo 6'te sunulmuştur. 
Tablo 6: Asimetrik Nedensellik Test Sonuçları

\begin{tabular}{|c|c|c|c|c|c|}
\hline \multirow[t]{2}{*}{ Hatemi J Asimetrik Nedensellik } & \multirow[t]{2}{*}{ Test İstatistiği } & \multicolumn{3}{|c|}{ Bootstrap Kritik Değerler } & \multirow{2}{*}{$\begin{array}{l}\text { Nedensellik } \\
\text { İlişkisi }\end{array}$} \\
\hline & & $1 \%$ & $5 \%$ & $10 \%$ & \\
\hline Kamu Dış Borcu ${ }^{+} \ldots \rightarrow$ CDS $^{+}$ & 65.323 & 15.767 & 10.526 & 8.805 & Var \\
\hline Kamu Dış Borcu ${ }^{+} . .$. CDS $^{-}$ & 15.656 & 13.441 & 9.107 & 6.916 & Var \\
\hline Kamu Dış Borcu- $\cdots . . \mathrm{CDS}^{+}$ & 0.771 & 14.929 & 10.834 & 8.625 & Yok \\
\hline Kamu Dış Borcu' $\cdots . .$. CDS $^{-}$ & 1.306 & 8.768 & 4.66 & 2.952 & Yok \\
\hline $\mathrm{CDS}^{+} \ldots . . \mathrm{Kamu}$ Dış Borcu ${ }^{+}$ & 15.321 & 16.352 & 11.417 & 9.295 & Var \\
\hline $\mathrm{CDS}^{+} \ldots \rightarrow \mathrm{Kamu}$ Dış Borcu${ }^{-}$ & 48.873 & 17.69 & 12.771 & 10.555 & Var \\
\hline CDS $^{-} \cdots$ Kamu Dış Borcu $^{+}$ & 13.701 & 13.102 & 8.405 & 6.731 & Var \\
\hline CDS $^{-} \cdots$ Kamu Dış Borcu $^{-}$ & 59.532 & 12.319 & 7.506 & 5.289 & Var \\
\hline
\end{tabular}

Kamu dış borcu ve CDS primi değişkenleri bileşenlerine ayrılarak aralarındaki nedensellik ilişkisi incelendiğinde kamu dış borcundaki pozitif bir şokun CDS primlerindeki pozitif ve negatif şokların bir nedeni olduğu ancak kamu dış borcundaki negatif bir şokun CDS primlerinin ne negatif ne de pozitif şoklarının bir nedeni olmadı̆̆ını göstermektedir. Elde edilen bulgular CDS primlerindeki pozitif veya negatif bir şokun ise kamu dış borcundaki pozitif ve negatif şokların bir nedeni olduğunu göstermektedir. Özel sektör dış borcu ve CDS primlerinin pozitif ve negatif bileşenlerine ilişkin Hatemi-J (2012) asimetrik nedensellik test sonuçları Tablo 7'te sunulmuştur.

Tablo 7: Asimetrik Nedensellik Test Sonuçları

\begin{tabular}{|c|c|c|c|c|c|}
\hline \multirow[t]{2}{*}{ Hatemi J Asimetrik Nedensellik } & \multirow[t]{2}{*}{ Test İstatistiği } & \multicolumn{3}{|c|}{ Bootstrap Kritik Değerler } & \multirow{2}{*}{$\begin{array}{c}\text { Nedensellik } \\
\text { iliş̧kisi }\end{array}$} \\
\hline & & $1 \%$ & $5 \%$ & $10 \%$ & \\
\hline Özel Sektör Dış Borcu ${ }^{+} \ldots \rightarrow$ CDS $^{+}$ & 6.416 & 8.883 & 4.78 & 3.439 & Var \\
\hline Özel Sektör Dış Borcu ${ }^{+} . . . \rightarrow$ CDS$^{-}$ & 0.052 & 7.665 & 4.357 & 3.141 & Yok \\
\hline Özel Sektör Dış Borcu' $\cdots \rightarrow$ CDS $^{+}$ & 9.377 & 9.956 & 6.773 & 5.069 & Var \\
\hline Özel Sektör Dış Borcu $\rightarrow \rightarrow$ CDS $^{-}$ & 3.653 & 8.176 & 4.408 & 3.017 & Yok \\
\hline $\mathrm{CDS}^{+} \ldots .$. Özel Sektör Dış Borcu $^{+}$ & 0.23 & 6.933 & 3.92 & 2.807 & Yok \\
\hline $\mathrm{CDS}^{+} \ldots . . \mathrm{O}$ Özel Sektör Dış Borcuna- & 6.801 & 11.012 & 6.395 & 4.723 & Var \\
\hline CDS $^{-} \rightarrow \rightarrow$ Özel Sektör Dış Borcu ${ }^{+}$ & 0.357 & 7.854 & 4.101 & 2.91 & Yok \\
\hline CDS $^{-} \rightarrow \rightarrow$ Özel Sektör Dış Borcu ${ }^{-}$ & 0.182 & 6.652 & 4.013 & 2.804 & Yok \\
\hline
\end{tabular}

Elde edilen bulgulara özel sektör dış borcundaki pozitif ve negatif şokların CDS risk primindeki pozitif şokların bir nedeni olduğu ancak özel sektör dış borcundaki pozitif ve negatif şokların CDS risk primi negatif şoklarının bir nedeni olmadığı belirlenmiştir. Diğer taraftan CDS risk primlerindeki pozitif şok özel sektör dış borcundaki negatif şokun bir nedeni iken CDS risk primlerindeki pozitif şokun CDS risk primi pozitif şokunun ve CDS risk primindeki negatif şokun özel sektör dış borcunun ne pozitif ne de negatif şokunun bir nedeni olmadığı tespit edilmiştir.

\section{Sonuç}

Bu çalışma Türkiye'nin CDS risk primleri ile dış borcu arasında bir nedensellik ilişkinin var olup olmadığını araştırmaktadır. Türkiye'nin dış borcu, kamu ve özel sektör dış borcu olarak iki şekilde ele alınmaktadır. Çalışmada geleneksel asimptotik dağılım yerine bootstrap simülasyonuna dayalı dağılım kullanılmaktadır. Değişkenler arasındaki geleneksel nedensellik ilişkisi ile pozitif ve negatif şoklar arasındaki nedensellik ilişkisi farklı sonuçlar ortaya koyabilmesinden dolayı değişkenler arasındaki ilişki hem simetrik hem de asimetrik nedensellik testleri aracılığıyla ortaya çıkarılmaktadır. Ampirik bulgular Türkiye'nin kamu dış borcu ve özel sektör dış borcu ile CDS risk primleri arasındaki nedensellik ilişkisinin farklılıklar içerdiğini göstermektedir. CDS risk primleri ile kamu dış borcu arasında çift yönlü bir nedensellik ilişkisi tespit edilirken CDS risk primleri ile özel 
sektör dış borcu arasında herhangi bir nedensellik ilişkisinin var olmadığı sonucuna ulaşılmaktadır. Değişkenler arasındaki simetrik nedensellik ilişkisinin gösterdiği bu sonuçların aksine özel sektör dış borcundaki pozitif veya negatif bir şokun CDS'deki pozitif şokların, CDS'deki pozitif bir şokun ise özel sektör dış borcundaki negatif bir şokun nedeni olduğunu göstermektedir. Diğer taraftan kamu dış borcundaki negatif şokların CDS'deki pozitif ve negatif şokların bir nedeni olmadığı ancak bunun dışında kamu dış borçları ile CDS'de pozitif ve negatif şokların birbirlerinin bir nedeni olduğu sonucuna ulaşılmaktadır.

\section{Kaynakça}

Aizenman, J. Jinjarak, Y. ve Park, D. (2016). Fundamentals and Sovereign Risk of Emerging Markets. Pacific Economic Review, 21(2), 151-177. doi:10.1111/1468-0106.12160

Akçelik, F. ve Fendoğlu, S. (2019). Country Risk Premium and Domestic Macroeconomic Fundamentals When Global Risk Appetite Slides. CBRT Research Notes in Economics, No.19/04, 1-11.

Akkaya, M. (2017). Türk Tahvillerinin CDS Primlerini Etkileyen İçsel Faktörlerin Analizi. Maliye Finans Yazıları, 1(107), 129-146. doi:10.33203/mfy.307177

Badaoui, S., Cathcart, L. ve El-Jahel, L. (2013). Do Sovereign Credit Default Swaps Represent A Clean Measure of Sovereign Default Risk? A Factor Model Approach. Journal of Banking and Finance, 37(7), 2392-2407. doi:10.1016/j.jbankfin.2013.01.038

Bellas, D., Papaioannou, M. ve Petrova, I. (2010). Determinants of Emerging Market Sovereign Bond Spreads: Fundamentals vs Financial Stress. IMF Working Paper, WP/10/281, 1-23.

Blanco, R., Brennan, S. ve Marsh, I. (2005). An Empirical Analysis of the Dynamic Relation between Investment-Grade Bonds and Credit Default Swaps. The Journal of Finance, 60(5), 22552281. doi:10.1111/j.1540-6261.2005.00798.x

Bulow, J. ve Rogoff, R. (1989). Sovereign Debt: Is to Forgive to Forget? The American Economic Review, 79(1), 43-50.

Calice, G., Chen, J. ve Williams, J. (2013). Liquidity Spillovers in Sovereign Bond and CDS Markets: An Analysis of the Eurozone Sovereign Debt Crisis. Journal of Economic Behavior and Organization, 85(January), 122- 143. doi:10.1016/j.jebo.2011.10.013

Chen, Y., Saffar, W., Shan, C. ve Wang, S. (2018). Credit Default Swaps and Corporate Debt Structure. 1-48. doi:10.2139/ssrn.3170485

Eichengreen, B. ve Mody, A. (1998). What Explains Changing Spreads on EM Debt: Fundamentals or Market Sentiment? NBER Working Paper, No.6408, 1-45.

Eyssell, T., Fung, H. ve Zhang, G. (2013). Determinants and Price Discovery of China Sovereign Credit Default Swaps. China Economic Review, 24(March), 1-15. doi:10.1016/j.chieco.2012.09.003

Fontana, A. ve Scheicher, M. (2010). An Analysis of Euro Area Sovereign Cds and Their Relation with Government Bonds. European Central Bank, Working Paper Series No.1271, 1-49.

Granger, C. (1969). Investigating Causal Relations by Econometric Models and Cross-spectral Methods. Econometrica, 37(3), 424-438. doi:10.2307/1912791

Granger, C. ve Yoon, G. (2002). Hidden Cointegration. University of California Economics Working Paper No. 2002-02, 1-49. doi:10.2139/ssrn.313831

Hassan, M. (2013). Determinants of credit default swaps spreads in European and Asian markets. Journal of Derivatives and Hedge Funds, 19(4), 295-310. doi:10.1057/jdhf.2014.1 
Hacker, R. ve Hatemi-J, A. (2006). Tests for Causality between Integrated Variables Using Asymptotic and Bootstrap Distributions: Theory and Application. Applied Economics, 38(13), 1489-1500. doi:10.1080/00036840500405763

Hatemi-J, A. (2012). Asymmetric Causality Tests with An Application. Empirical Economics, 43(1), 447-456.

Hernandez-Trillo, F. (1995). A Model-Based Estimation of the Probability of Default In Sovereign Credit Markets. Journal of Development Economics, 46(1), 163-179. doi:10.1016/03043878(94)00053-F

Ho, S. (2016). Long and Short-Runs Determinants of the Sovereign CDS Spread in Emerging Countries. Research in International Business and Finance, 36(January), 579-590. doi:10.1016/j.ribaf.2015.07.001

Ismailescu, I. ve Phillips, B. (2015). Credit Default Swaps and the Market for Sovereign Debt. Journal of Banking and Finance, 52(March), 43-61. doi:10.1016/j.jbankfin.2014.10.015

Kapadia, N. ve Pu, X. (2012). Limited Arbitrage between Equity and Credit Markets. Journal of Financial Economics, 105(3), 542-564. doi:10.1016/j.jfineco.2011.10.014

Kamin, S. ve Kleist, K. (1999). The Evolution and Determinants of EM Credit Spreads in the 1990s. International Finance Discussion Paper, No. 653, 1-46.

Kılcı, E. (2019). Dış Borçların Ülke CDS Primleri Üzerindeki Etkisinin İncelenmesi: Türkiye Örneği. Sayıştay Dergisi, 112, 75-92.

Kocsis, Z. ve Monostori, Z. (2016). The role of country-specific fundamentals in sovereign CDS spreads: Eastern European experiences. Emerging Markets Review, 27(June), 140-168. doi:10.1016/j.ememar.2016.05.003

Longstaff, F., Mithal, S. ve Neis, E. (2005). Corporate Yield Spreads: Default Risk or Liquidity? New Evidence from the Credit Default Swap Market. The Journal of Finance, 60(5), 2213-2253. doi:10.1111/j.1540-6261.2005.00797.x

Mellios, C. ve Paget-Blanc, E. (2006). Which Factors Determine Sovereign Credit Ratings?. The European Journal of Finance, 12(4), 361-377. doi:10.1080/13518470500377406

Min, H. (1998). Determinants of Emerging Market Bons Spread: Do Economic Fundamentals Matter? Policy Research Working Paper, No. 1899, 1-31. doi:10.1596/1813-9450-1899

Panetta, F., Faeh, T., Grande, G., Ho, C., King, M., Levy, A. ve Zaghini, A. (2009). An Assessment of Financial Sector Rescue Programmes. Bank for International Settlements, BIS Paper No.48, 1-77.

Qian, Z., Wang, W. ve Ji, K. (2017). Sovereign Credit Risk, Macroeconomic Dynamics, And Financial Contagion: Evidence From Japan. Macroeconomic Dynamics, 21(8), 2096-2120. doi:10.1017/S1365100516000122

Toda, H. ve Yamamoto, T. (1995). Statistical Inference in Vector Autoregressions with Possibly Integrated Processes. Journal of Econometrics, 66(1-2), 225-250. doi:10.1016/03044076(94)01616-8

Tolikas, K. ve Topaloglou, N. (2017). Is Default Risk Priced Equally Fast in the Credit Default Swap and the Stock Markets? An Empirical Investigation. Journal of International Financial Markets, Institutions and Money, 51(November), 39-57. doi:10.1016/j.intfin.2017.09.029

Wang, A., Yang, S. ve Yang, N. (2013). Information Transmission between Sovereign Debt CDS and other Financial Factors - The Case of Latin America. The North American Journal of Economics and Finance, 26(December), 586-601. doi:10.1016/j.najef.2013.02.02 
Yılmaz, A. ve Ünlü, A. (2018). Effect of Some Macroeconomic Variables on Risk Perception: The Turkish Case. Hacettepe University Journal of Economics and Administrative Sciences, 36(4), 117-147. doi:10.17065/huniibf.320139 
THE RELATIONSHIP BETWEEN CDS RISK PREMIUM AND EXTERNAL DEBT: SYMMETRIC AND ASYMMETRIC CAUSALITY ANALYSIS

\section{Extended Abstract}

Aim: The purpose of this study is to reveal the relationship between external debt and CDS risk premium. There are two important issues that distinguish the study from other studies in the literature. First, the distinction is made that external debt is private sector debt and public sector debt. Thus, it is aimed to determine whether the increases or decreases in the CDS premium significantly changes the structure of private and public sector external debt. Secondly, it is aimed to reveal the effects of positive or negative shocks in private sector external debt, public sector external debt and CDS premiums by analyzing them separately.

Method(s): In the study, the existence of the relationship between public external debt and private sector external debt and CDS premiums is revealed through Hacker and Hatemi-J (2006) causality test and Hatemi-J (2012) asymmetric causality tests. Toda and Yamamoto (1995) propose a simple way to overcome problems in the hypothesis testing encountered when there may be unit roots in the VAR process. Toda and Yamamoto (1995) test the linear or nonlinear constraints on the coefficients by estimating the VAR with the level of series and applying the Wald criterion. Hacker and Hatemi-J (2006) emphasize that the test statistics related to the Wald criterion may be weak in cases where the sample size is low and therefore the distribution based on bootstrap simulation is stronger instead of using traditional asymptotic distribution. The causality relationship between variables is tried to be revealed without separating the variables into their positive and negative components through Hacker and Hatemi-J (2006) causality test. However, the variables are separated into positive and negative components in Hatemi-J (2012) asymmetric causality test and causality relationship is investigated between positive and negative components.

Findings: While the empirical findings of the study reveal the existence of a bidirectional causality relationship between public external debt and CDS risk premium, there was no causal relationship between private sector external debt and CDS risk premium. It has been determined that a positive shock in public external debt is a cause of positive and negative shocks in CDS premiums, but a negative shock in public external debt is not a cause of CDS premium components. While it is determined that positive and negative shocks in private sector external debt are a cause of positive shocks in CDS risk premium, it is concluded that positive shock in CDS risk premiums is a cause of negative shock in private sector external debt.

Conclusion: Since the traditional causality relationship between variables and causality relationship between positive and negative shocks can produce different results, the relationship between variables is revealed through both symmetric and asymmetric causality tests. In the study, the distribution based on bootstrap simulation is used instead of the traditional asymptotic distribution. The causal relationship between Turkey's public external debt and the private sector external debt and CDS risk premium indicates several differences. While a bidirectional causality relationship is determined between CDS risk premiums and public external debt, it is concluded that there is no causality relationship between CDS risk premiums and private sector external debt. Contrary to the results demonstrated by the symmetric causality relationship between the variables, it indicates that a positive or negative shock in the private sector external debt is the cause of positive shocks in the CDS, and a positive shock in the CDS is the cause of a negative shock in the private sector external debt. On the other hand, it is concluded that negative shocks in public external debt are not a cause of positive and negative shocks in CDS. However, the positive and negative shocks occurring in public external debt and CDS risk premium are also a cause of each other. 
